\title{
Skin complication of insulin pump therapy - contact dermatitis from patch pump adhesive
}

\author{
NINA DUTTA ${ }^{1}$, DENISE CROSSAN ${ }^{1}$, NEIL MUNRO ${ }^{1,2,3}$, MICHAEL FEHER ${ }^{1,2,4}$
}

\section{Background}

Insulin pump therapy or CSII is increasingly used for the delivery of insulin. ${ }^{1}$ There are several corded pumps and one non-corded (patch) pump currently in the UK market. Technical advances have led to increasingly safe insulin pump therapy, however there are still hazards of DKA, cannula site infection and potential skin complications. Patch pumps require a broader base adhesive contact to the skin compared to that required to cover the cannula sites of the corded pumps. ${ }^{2}$

\section{Case description}

We report a case of contact dermatitis associated with patch pump therapy in a 56 year old male who has had type 1 diabetes for 39 years. He required CSII treatment for recurrent hypoglycaemia and sub-optimal glycaemic control. The rash developed under the contact adhesive (see Figure 1) when he started using the second generation of the patch pump, but had no issues using the older version. Extensive investigations have not ascertained the cause of this. Topical steroids were required as well as the withdrawal of the pump therapy in order to manage the skin changes.

\section{Discussion}

With the expanding use of insulin pump therapies, clinical hazards beyond glucose control may be a therapeutic challenge. Contact dermatitis associated with insulin pump adhesives may be initially managed with barrier creams such as Cavilon, topical steroids, patch testing to diagnose a specific allergy and occasionally withdrawal of a specific pump. ${ }^{3}$ Additionally, more specific details of the contents of the adhesives need to be made available from all pump manufacturers.

This case highlights that diabetologists need to be more skilful in the management of specific diabetes skin conditions and side effects of treatments.

Beta Cell Diabetes Centre, Chelsea and Westminster NHS Foundation Trust, London, UK

2 Diabetes Therapies Evaluation Network, London, UK

Department of Healthcare Management and Policy, University of Surrey, UK

${ }^{4}$ Warwick Medical School, Warwick University, Warwick, UK

Address for correspondence: Dr Nina Dutta

Beta Cell Diabetes Centre, Chelsea and Westminster NHS Foundation

Trust, 369 Fulham Road, London, SW10 9NH, UK

Tel: $+44(0) 7917446236$

E-mail: n.dutta@imperial.ac.uk

Br J Diabetes Vasc Dis 2014;14:116

http://dx.doi.org/10.15277/bjdvd.2014.023

\author{
Abbreviations and acronyms \\ CSII \\ DKA \\ continuous subcutaneous insulin infusion \\ diabetic ketoacidosis
}

Figure 1. Area of contact dermatitis from adhesive of the patch pump
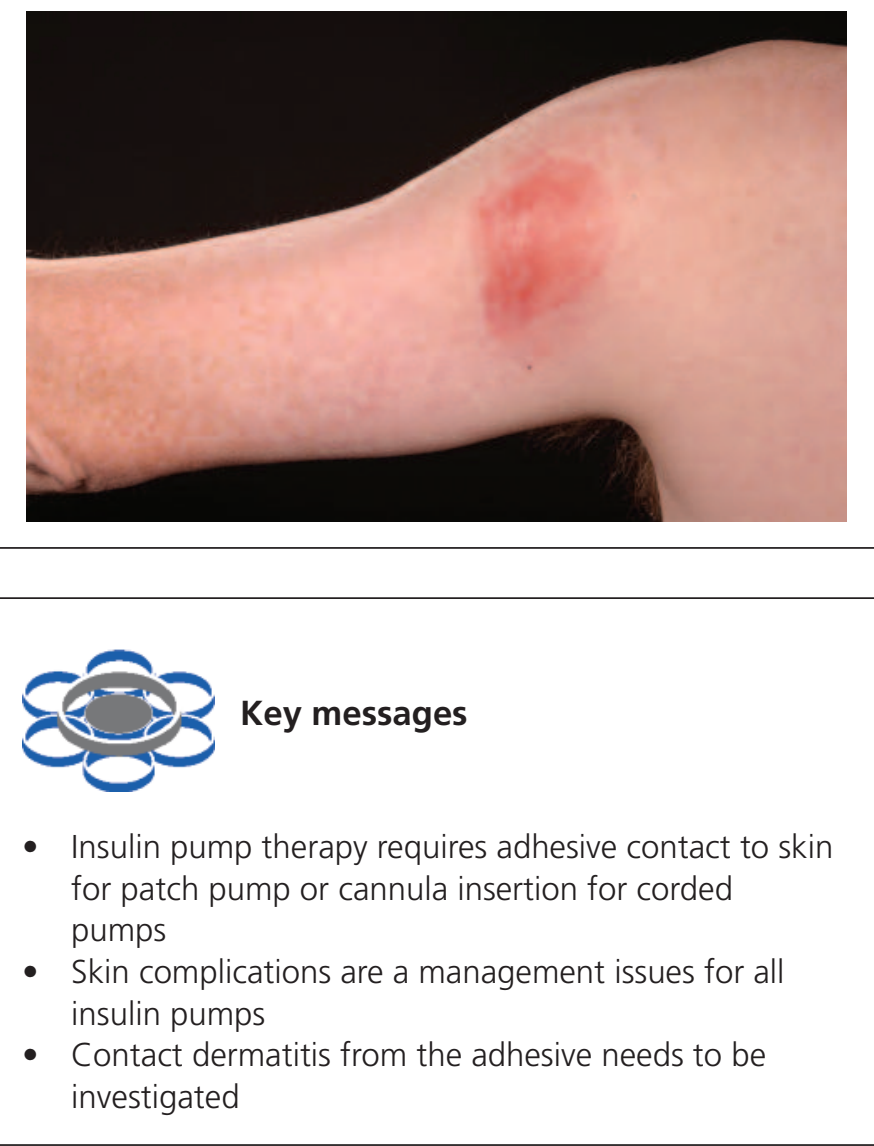

\section{Conflict of interest None.}

\section{References}

1. Wilmot E, Choudhary P, Grant P, Hammond P. Insulin pump therapy: a practical guide to optimising glycaemic control. Practical Diabetes 2014;31(3):121-5a. http://dx.doi.org/10.1002/pdi.1846

2. Annaholt H, Bohannon NJV. Insulin patch pumps. Diabetes Technol Ther 2010;12(Suppl 1):S-51-S-58.

3. Saary J, Qureshi R, Palda V et al. A systematic review of contact dermatitis treatment and prevention. J Am Acad Dermatol 2005;53(5):845 